\title{
Assessment on the Efficiency of an Active Solar Thermal Facade: Study of the Effect of Dynamic Parameters and Experimental Analysis When Coupled/Uncoupled to a Heat Pump ${ }^{\dagger}$
}

\author{
Peru Elguezabal $^{1, *(1)}$, Alex Lopez ${ }^{2}{ }^{\oplus}$, Jesus Maria Blanco ${ }^{2}\left(\mathbb{D}\right.$ and Jose Antonio Chica ${ }^{1}$ \\ 1 TECNALIA, Basque Research and Technology Alliance (BRTA), Astondo Bidea, Edificio 700, Parque \\ tecnológico de Bizkaia, 48160 Derio, Spain; joseantonio.chica@tecnalia.com \\ 2 Department of Nuclear Engineering and Fluid Mechanics, School of Engineering, UPV/EHU, Plaza Ingeniero \\ Torres Quevedo 1, 48013 Bilbao, Spain; alopez140@ehu.eus (A.L.); jesusmaria.blanco@ehu.eus (J.M.B.) \\ * Correspondence: peru.elguezabal@tecnalia.com \\ + Partial content of this paper was presented at the 4th Central European Symposium on Building Physics \\ CESBP-2019, Prague 2-5 September 2019.
}

Received: 5 December 2019; Accepted: 20 January 2020; Published: 29 January 2020

\begin{abstract}
The building sector presents poor performance in terms of energy efficiency and is looking for effective alternatives aimed at reducing the use of fossil fuels. The facade is a key element able to harness renewable energy as an Active Solar Thermal Facade (ASTF). The main purpose of this study is the assessment of a novel design concept based on a steel sandwich panel technology. The performance of the active system will be first addressed by a parametric study in order to analyze its behavior and secondly, by describing a real case based on an experimental test by connecting the active panels to a heat pump. The study shows the impact of solar irradiation and mass flow on the thermal jump achieved, while ambient and fluid inlet temperatures are the most influencing parameters in the efficiency of the facade. When coupled to the heat pump, results from a measurement campaign demonstrate a remarkable improvement in the performance of the ASTF. The results presented provide significant proof about the benefits of a synergetic combination of both technologies-solar facades and heat pumps-as efficient alternatives for the building sector, aiming to improve energy efficiency as well as reduce their dependence on non-renewable sources.
\end{abstract}

Keywords: active solar thermal facade; sandwich panels; thermal efficiency; unglazed collector; solar assisted heat pumps

\section{Introduction}

Current trends to develop efficient solutions aiming to decarbonize the building sector need to provide concepts that can effectively reduce the energy bill of buildings, while increasing the contribution from renewables. Development in the next years of new and modern buildings, equipped with the latest technologies, will contribute to getting closer to the Nearly Zero Energy Buildings (NZEB) solution [1].

Solar thermal energy has demonstrated a high potential that is being widely developed thanks to the pull of renewable industry. Active Solar Thermal Facades (ASTF) as integrated energy harvesting solutions contributing to more efficient heating and cooling production, are becoming of paramount interest for the ongoing transformation of the building sector. Currently different alternatives are available in the market, together with many research initiatives which are under development, implementing and demonstrating the benefits of these types of combined solutions [2]. There is no a 
unique solution but a wide variety of technologies and different combinations that can transform the sector moving towards the NZEB concept.

In such a scenario, ASTF also represents a very promising concept [3,4] aiming to incorporate Renewable Energy Sources (RES) to the building. As the interface connecting the interior of the building, where comfort is a priority, to the exterior under variable environmental conditions, the opportunity directly assigned to the facade as a bridge to connect renewable energy sources to the building has been clearly identified [5-7]. There is a significant variety of technologies for ASTFs with different degrees of sophistication [8,9]. New developments have been presented over the past few years [10-17], however, the presence of these solutions are still considered testimonial [18], due to inadequate approaches and the high resistance to incorporate changes in this sector.

In parallel, heat pumps are becoming of great interest as a low energy solution able to fully cover the requirements of buildings while making an efficient use of the energy. The European Union has even established that for reference values of the Seasonal Performance Factor (SPF) above 2.5, this technology is considered as a renewable solution [19].

A combination of heat pumps with solar technologies, under the Solar Assisted Heat Pump (SAHP) concept, has already been described in previous research initiatives [20-26], although the available information and the experiences combining both technologies are still too scarce and very focused only on standard solar systems. Therefore, there is an increasing need to better understand the interaction and combination of both concepts-ASTFs and heat pumps-to provide additional knowledge about the promising potential of both systems when working coupled.

The study described in the present work is arranged under a two-step approach. First an innovative ASTF is studied, assessing the response of that concept under variable dynamic conditions by means of a parametric study. In the second step, the interaction of that active facade solution with a heat pump is quantified, comparing the performance of each component, when working independently (uncoupled), against the coupled operation mode of the combined SAHP system.

This research is focused on the behavior of a low-temperature ASTF connected to a water-to-water heat pump. The system was developed as part of a research project [27] finished in 2016, where the design of an innovative unglazed solar panel based on steel sandwich technology was developed and its interconnection to a heat pump was preliminary defined. As a result, the system was installed on Tecnalia's Kubik ${ }^{\circledR}$ experimental building in Derio, Spain. This facility has a total surface of $18 \mathrm{~m}^{2}$ composed by six prototype active panels connected to the source side of a $6 \mathrm{~kW}$ electrically-driven water-to-water heat pump. Initial tests demonstrated the potential of the system to produce heat for both space heating and domestic hot water (DHW) purposes [28].

Promoting the use of systems based on well-known and proven technologies, through a new generation of innovative systems, is the main purpose of this study. Looking for efficient management of energy, these outcomes are of special interest for the building industry as such concepts will be required in the upcoming years, looking forward to improving energy efficiency in buildings as well as reducing their strong dependency on fossil fuels.

\section{Materials and Methods}

The interest of the current study is to better understand the implications on the performance of those two main components, the ASTF and the heat pump. First, the active facade is analyzed independently and later, the interaction with the heat pump is considered, aiming to compare their response as individual elements and when coupled working under a synergetic approach. In this way the potential of the active facade and of the combined system can be estimated in terms of the quantity of energy that can be harnessed and produced. Thus, valid expressions to evaluate the performance of each individual component are required.

On the one hand, for the ASTF, efficiency is the main parameter that characterizes its behavior. As indicated in Equation (1) [29], efficiency is a relation between useful energy $(Q)$ and incident solar energy $\left(I_{\text {sol }}\right)$ into the collector's surface $\left(A_{C}\right)$. Useful energy is defined as a function of the temperature 
difference between the fluid inlet and outlet $\left(T_{\text {out }}-T_{\text {in }}\right)$ throughout the collector, as described in Equation (2), with $\dot{m}$ as the mass flow rate and $C_{W}$ as the specific heat of water.

These two factors, performance and useful energy, should be maximized but the relationship between these two is not direct. It could be that for high efficiency the useful energy is insufficient or that, on the contrary, there is enough energy values even for modest efficiencies in the collector. In any case, it is necessary to adjust the design according to the intended application with the aim of maximizing the performance of the system for the expected efficiency and/or production rate.

$$
\begin{gathered}
\eta=\frac{Q}{A_{c} I_{\text {sol }}} \\
Q=\dot{m} C_{w}\left(T_{\text {out }}-T_{\text {in }}\right)
\end{gathered}
$$

On the other hand, for the heat pump, the coefficient of performance (COP) of electrically-driven heat pumps is the main factor considered for the evaluation of the performance. This factor is the ratio between the extracted thermal output and the consumed electricity, as described in Equation (3). Therefore, it represents how many $\mathrm{kW}$ of heating can be generated from $1 \mathrm{~kW}$ of electricity input. When the heat pump is used for cooling production, the equivalent factor is the energy efficiency ratio (EER), combining the cooling capacity and the consumed electrical power.

For COP estimation, $Q_{H}$ is the heat delivered by the condenser in heating mode operation of the heat pump and $W_{C}$ is the associated electrical energy consumed by the compressor.

$$
C O P=\frac{Q_{H}}{W_{c}}
$$

Electricity can be accounted just for the heat pump or for the complete system (including additional circulating pumps and devices). When the scope of the analysis is wider and covers additional components consuming electricity apart from the heat pump, the electricity consumption indicated in the denominator of the previous equation will increase, reducing the overall efficiency. In that case, the electricity associated to the auxiliary equipment is considered. This extra consumption is identified as $W_{\text {aux }}$ (Equation (4)).

$$
W_{\text {aux }}=\sum_{1}^{n} W_{\text {consumer } n}
$$

Depending on the system's boundary definition, the above indicated electricity consumers will be taken into consideration as part of the system or not. As a consequence, the resulting system's efficiency is then calculated according to Equation (5).

$$
\mathrm{COP}_{\text {Sys }}=\frac{Q_{H}}{W_{C}+W_{\text {aux }}}
$$

\subsection{Experimental Set-up}

The assessment carried out in the following sections is based on the analysis of the experimental data for the complete system installed as a continuation of previous research [30]. Figure 1 represents the general scheme of the system as installed in the Kubik ${ }^{\circledR}$ experimental building. Specific devices are available for the evaluation of the efficiencies for both the active facade and the heat pump. 

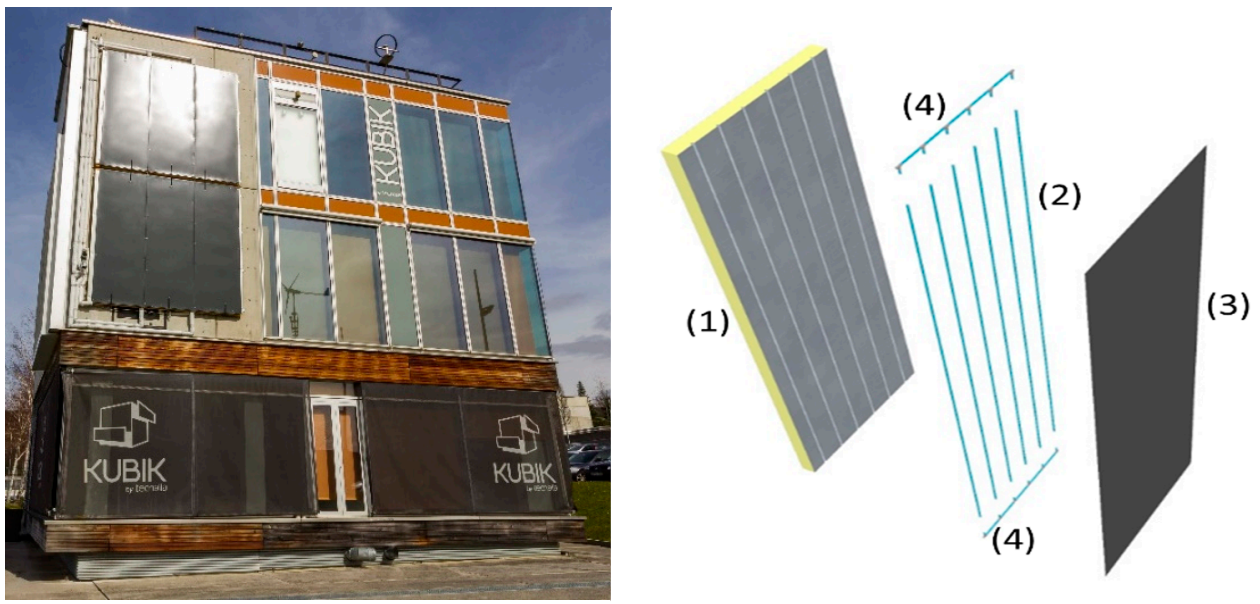

Figure 1. Unglazed solar collector installed on the building's south oriented facade (left). Sandwich panel integrating the unglazed solar collector splitting the main components of the solution (right). Sandwich panel (1), nylon pipes (2), steel cover (3) and header elements (4).

The ASTF was installed on the south wall of this facility at Derio headquarters $\left(43^{\circ} 17^{\prime} 44.9^{\prime \prime} \mathrm{N} / 2^{\circ} 52^{\prime} 16.9^{\prime \prime} \mathrm{W}\right)$, Spain (Figure 1, left). A total of six active panels $\left(3 \mathrm{~m}^{2}\right.$ each) was fitted over one of the facades of the building and the resulting design of those initial prototypes consisted of four main components for each panel (Figure 1, right), such as: the sandwich panel (1) with a polyurethane insulation core combined with two slotted steel skins. Nylon pipes (2) installed into the slots of the external skin to be later completed with the final steel cover (3) acting as a solar absorber. Each panel includes six parallel tubes and modular header elements (4) are also provided inside for interconnecting them. Dimensions of the standard panel are $3 \mathrm{~m}$ length, $1 \mathrm{~m}$ wide, and $0.08 \mathrm{~m}$ thick. Steel sheets, nylon pipes, and polyurethane insulation were the main materials used, whose conductivities are respectively, $50 \mathrm{~W} / \mathrm{m}^{2} \mathrm{~K}, 0.2 \mathrm{~W} / \mathrm{m}^{2} \mathrm{~K}$, and $0.025 \mathrm{~W} / \mathrm{m}^{2} \mathrm{~K}$. The complete system was hydraulically connected to a storage tank, resulting in a solar loop where the fluid was circulated by a dedicated pump.

The combination of the active facade with the heat pump represents the full heat production system and is materialized by interconnecting these two main elements in the hydraulic system as shown below in Figure 2.

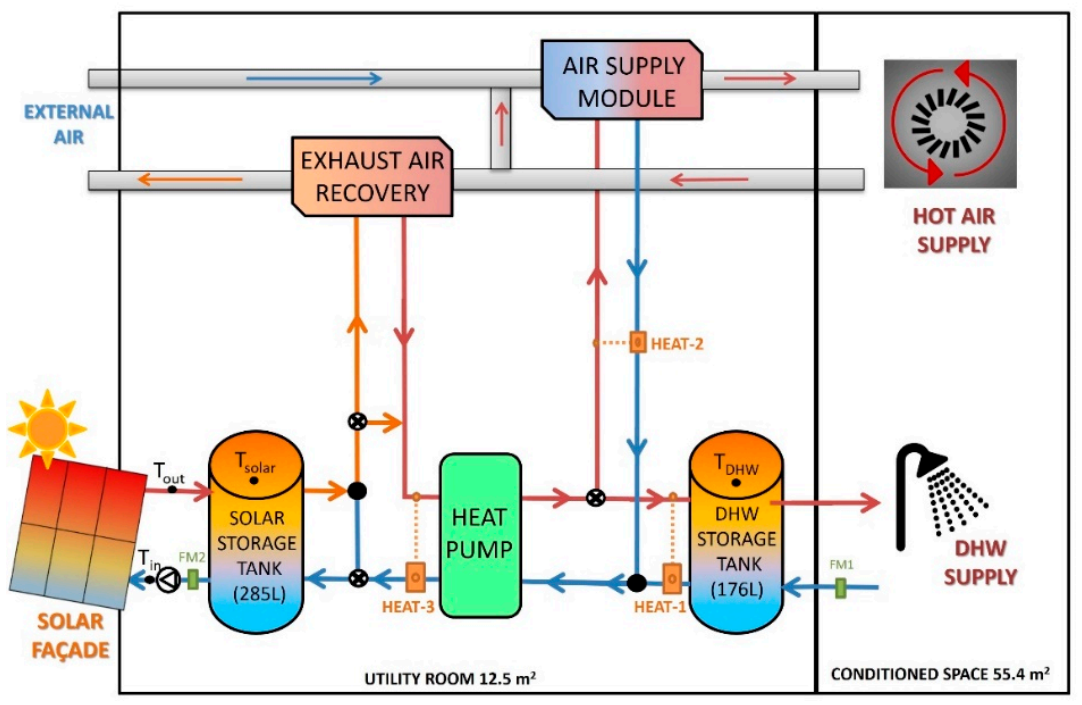

Figure 2. Scheme of the combined Active Solar Thermal Facade (ASTF) + heat pump system as installed at Kubik ${ }^{\circledR}$ building. 
The complete system described is designed to provide both hot air and domestic hot water (DHW), being the heat pump that feeds these two loads as the main heat power generator. On the source side of the heat pump connected to the evaporator, the solar loop is the main contributor, although the system has flexibility to incorporate a heat recovery system in series with the solar tank of the source side, by activating a pair of three-way valves. The load side of the heat pump distributes the hot water outgoing from the condenser to an air-to-water heat exchanger for heating the internal room, or the DHW storage tank. Depending on the demand needs, the heat pump controls another three-way valve to provide heat to one of these two loads at each time.

The electric input is related to the heat pump as the main consumer. Additional consumers are the circulating pump (to make the fluid run through the solar facade), as well as the air-to-water heat exchangers (air supply and exhaust air recovery modules).

The system was initially designed and installed with the possibility of producing heat or cold water as the heat pump is externally reversible. This connects the evaporator to the air supply module chilling the air, while the condenser is connected to the exhaust air module or to the DHW tank, depending on the needs. The main interest of the research developed in this case is the potential use of the thermal energy collected by the ASTF combined with the heat pump, whereas the cooling mode is out of the scope of this study as the temperature levels achieved are just valid for heating and DHW production and are insufficient for solar cooling applications. Therefore Figure 2 represents the hydraulic configuration for the hot production mode in a simplified scheme.

As was previously depicted in Figure 1 (left), the active panels were installed in the south facade while the heat pump, the storage tanks, and the air modules were installed in a utility room $\left(12.5 \mathrm{~m}^{2}\right)$ inside the experimental facility (Figure 2). Next to that utility room, as depicted in Figure 3 (right), an air-conditioned space of $55.4 \mathrm{~m}^{2}$ is heated by the air distribution system.
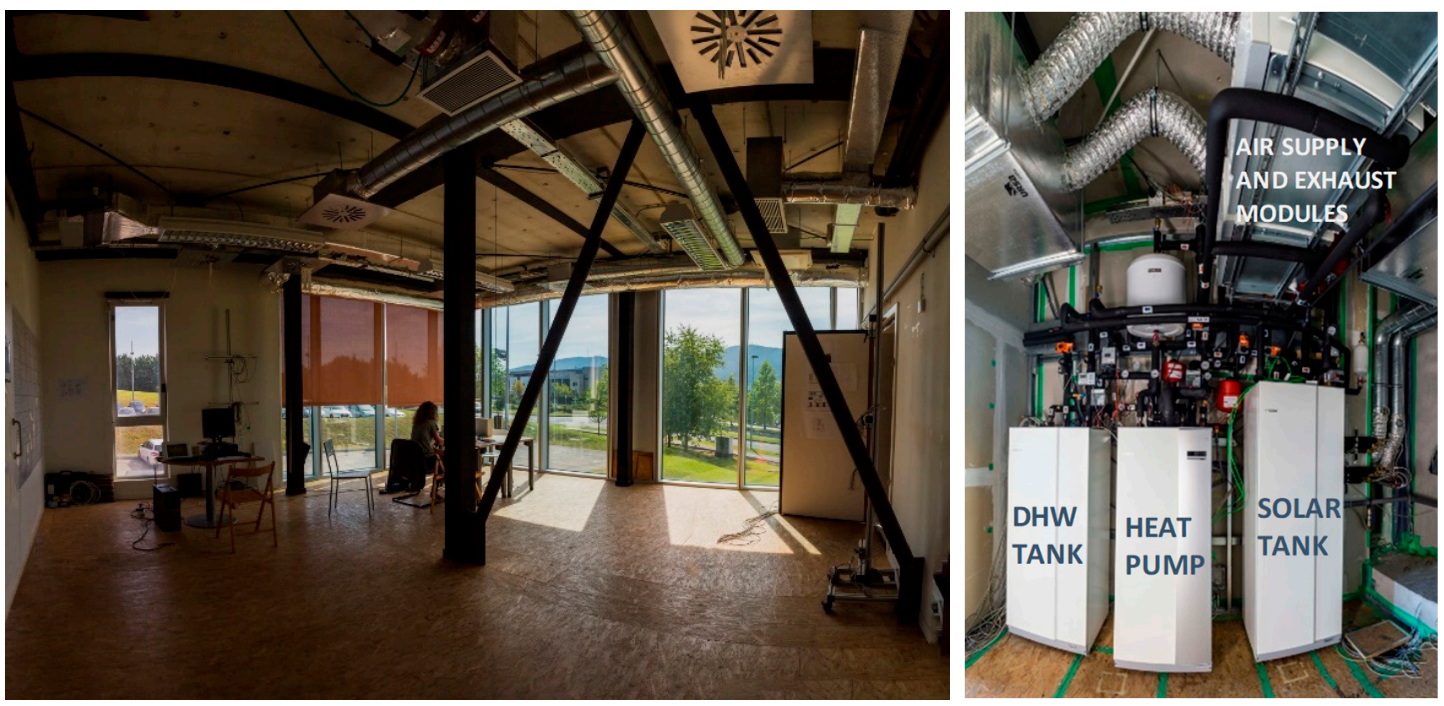

Figure 3. Air-conditioned space (left) and utility room (right).

The combined ASTF and heat pump solution is completed with the data acquisition system. For the solar loop, temperature sensors were located on the surface of the active panels. Additional temperature sensors were used to record the fluid's inlet $\left(T_{i n}\right)$ and outlet $\left(T_{\text {out }}\right)$ temperatures as well as the temperature levels in the middle and top parts of the solar storage tank. The flowmeter (FM) registers the mass flow $(\dot{m})$. The solar irradiance $\left(I_{s o l}\right)$ on the vertical south-oriented facade is recorded by a pyranometer located on the roof of the building. An anemometer inside a weather station on the roof also measures the external ambient temperature $\left(T_{a m b}\right)$, wind speed $\left(V_{w}\right)$, and wind direction $\left(D_{w}\right)$.

For the heat pump, the heat delivered is measured differentiating the contribution for DHW (heat-meter 1) from the energy used for space heating (heat-meter 2). The heat required by the heat 
pump that is absorbed through its source side is recorded by heat-meter 3. This low-level heat is provided by the solar circuit, by the exhaust recovery element, or by the combination of both. The electricity consumed by the heat pump and the rest of the components is recorded by smart meters. When the electricity consumption of all components is taken into account, the overall system's COP is also calculated (Equation (5)). Tables 1 and 2 describe the main components of the production system and the measurement equipment, respectively.

Table 1. Main components of the production system.

\begin{tabular}{ccc}
\hline Component & Type/Model & Description/Capacity \\
\hline Heat pump & F1155 by Nibe & $6 \mathrm{~kW}$ power. Electrically driven \\
Air supply module & SAM 40 (2 units) & $350 \mathrm{~W}$ and $600 \mathrm{~m}^{3} /$ air volume \\
Exhaust air module & FLM (2 units) & $350 \mathrm{~W}$ and $700 \mathrm{~m}^{3} /$ air volume \\
Solar pump & Wilo-stratos 25 & $140 \mathrm{~W}$ nominal power \\
Domestic hot water (DHW) tank & VPB 200 from Nibe & 285-L capacity \\
Solar tank & AHPS from Nibe & 176-L capacity \\
Actuators & Belimo & Motorized 3-way valve + actuator \\
\hline
\end{tabular}

Table 2. Description of the experimental measurement equipment.

\begin{tabular}{cccc}
\hline Parameter & Measurement Device & Type/Model & Uncertainty \\
\hline Surface temperature $\left({ }^{\circ} \mathrm{C}\right)$ & RTD-PT100 & Thermo Sensor GmBH & $\pm 0.1{ }^{\circ} \mathrm{C}$ \\
Fluid temperature in pipes and tanks $\left({ }^{\circ} \mathrm{C}\right)$ & RTD-PT100 & Thermo Sensor GmBH & $\pm 0.1{ }^{\circ} \mathrm{C}$ \\
Mass flow $(\mathrm{l} / \mathrm{min})$ & Ultrasonic Flowmeter & Kamstrupp Ultraflow & $\pm 0.0132 \mathrm{~L} / \mathrm{seg}$ \\
Solar irradiation $\left(\mathrm{W} / \mathrm{m}^{2}\right)$ & Pyranometer & Kipp \& Zonen CMP -6 & $\pm 5 \%$ \\
Wind speed $(\mathrm{m} / \mathrm{s})$ & Anemometer & Vaisala WXT520 & $\pm 3 \%$ \\
External air temperature $\left({ }^{\circ} \mathrm{C}\right)$ & RTD-PT100 & Vaisala WXT520 & $\pm 0.3{ }^{\circ} \mathrm{C}$ \\
Thermal power/energy $(\mathrm{kW} / \mathrm{kWh})$ & Heat-meter & Kamstrupp multical 402 & $\pm 2.15 \%$ \\
Electrical power $(\mathrm{W} / \mathrm{kWh})$ & Smart meter & Carlo Gavazzi EM 200 & $\pm 1.5 \%$ \\
\hline
\end{tabular}

The assessment presented has a double approach and both are linked to the prototype system described:

- First, to proceed on an assessment previously carried out, a study is developed by means of a parametric assessment, aiming to analyze the impact that changes on five dynamic factors have on the system's response. A numerical assessment is performed for this study, by means of a Computer Fluid Dynamic (CFD) model that was previously developed and validated using the data monitored for prototypes under real working conditions.

- Second, based on the analysis of the experimental data for the complete system installed, a comparison of the efficiency achieved by the ASTF and the heat pump both working separately and together is studied.

In the following sections, the way to proceed for each case is carefully described.

\subsection{Parametric Assessment of the ASTF}

This assessment is an extension of a previous study [30], where key design parameters for the panel and the circuit were analyzed highlighting the importance of the skin and pipe materials. In the current research an additional study for five different dynamic parameters was carried out. These dynamic parameters included fluid inlet temperature, mass flow rate, ambient temperature, solar irradiation, and wind speed.

Based on the ASTF prototype, a validated numerical model was developed using ANSYS FLUENT $^{\circledR}$ v18.2. This model was the tool used to simulate the dynamic parameters assessing the effect of these on both the performance and energy collected by the active facade.

The aim of the model was to calculate the heat transfer within solids and between solids and fluid which represents the two main thermal transfer processes inside the collector. The model allows to 
simulate the outlet temperature, a parameter that will allow to calculate the energy gained in the panel as the difference between inlet and outlet temperatures for certain mass flow rates (Equation (2)) as well as efficiency (Equation (1)). Combining Equations (1) and (2) the solar collector's efficiency is calculated by Equation (6).

$$
\eta=\frac{\dot{m} C_{w}\left(T_{o u t}-T_{\text {In }}\right)}{I_{\text {sol }} A_{c}}
$$

The incident solar radiation, $\left(q_{\text {irad }}\right)$, is transformed into a heat flux [31]. Thus, the heat absorbed by the exposed surface is equal to the product of solar irradiance and surface absorptance (Equation (7)).

$$
q_{\text {irad }}=\alpha I_{\text {sol }}
$$

The heat released back to the ambient by radiative and convective effects is described in Equation (8). The first term reflects the convective heat exchange as a function of the convective coefficient $\left(h_{w}\right)$ and the temperature difference between the absorber sheet $\left(T_{a b s}\right)$ and the ambient temperature $\left(T_{a m b}\right)$. The second term, as described in Equation (9), is the radiation emitted to the environment combining the emissivity $(\varepsilon)$ and Stefan-Boltzmann's constant $(\sigma)$.

$$
\begin{gathered}
q=h_{w}\left(T_{a m b}-T_{a b s}\right)+q_{r a d} \\
q_{r a d}=\varepsilon \sigma\left(T_{s k y}^{4}-T_{s}^{4}\right)
\end{gathered}
$$

For the energy equation, the conduction heat transfer governed by Fourier's law was considered. The heat flux absorbed by the internal flow through the pipe, $\left(q_{f}\right)$, is described by Equation $(10)$, with $h_{f}$ as the convective heat transfer coefficient between the fluid and pipe wall, $T_{f}$ as the fluid temperature, and $T_{p}$ as the pipe's wall temperature:

$$
q_{f}=h_{f}\left(T_{f}-T_{p}\right)
$$

All these assumptions are depicted as boundary conditions for the different sides of the computational domain in Figure 4, corresponding to a portion of the solar panel. The symmetry condition together with the parallel configuration of the pipes inside the collector enable a simplification of the system to a $100 \mathrm{~mm}$ long $\times 160 \mathrm{~mm}$ wide section containing one single pipe. The headers connecting the pipes in the top and bottom sides provide a uniform flow representing a small area compared to the complete surface of the collector, so it can be ignored in the calculation [29].
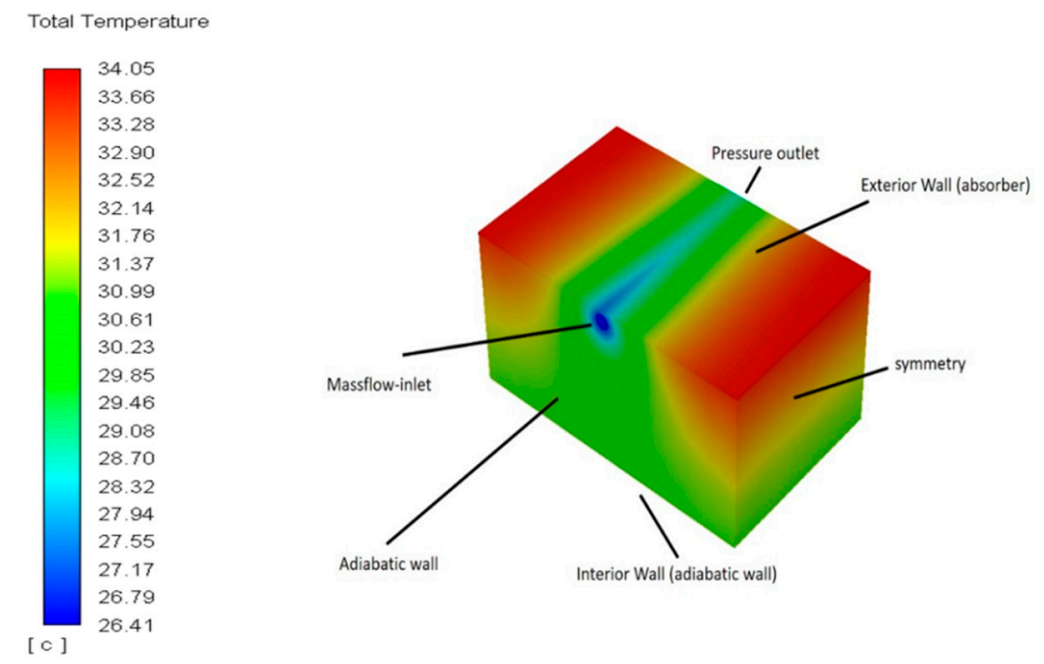

Figure 4. Three-dimensional-Computer Fluid Dynamic (3D)-CFD model, with the boundary conditions representing the computational domain of the solar panel. 
The convective heat transfer between the fluid zones and the corresponding faces is solved by coupling the momentum and energy equations, using a second order upwind. The SIMPLE (Semi-Implicit Method for Pressure Linked Equations) pressure-based solver was implemented for the pressure discretization.

To represent the fluid crossing the panel, an interior and exterior wall are defined in the model, as well as a mass flow inlet and pressure outlet. For the lateral faces, the symmetry condition allows the replica of multiple pipes to calculate the effect of several parallel pipes (six in the benchmark case) in the longitudinal axis. The width of the modeled section then determines the distance between parallel pipes under this approach.

Under steady-state conditions, the model simulates the heat transfer effects that have been described, estimating the absorber's surface temperature $\left(T_{a b s}\right)$ as well as the fluid's outlet temperature $\left(T_{o u t}\right) . T_{a m b}, T_{i n}$, and $\dot{m}$ are direct inputs to the model while the irradiation is transformed into a heat flux and the wind velocity is used to estimate the heat transfer coefficient $\left(h_{W}\right)$. Alternative environmental conditions can be used as inputs for the steady-state model when stable conditions are achieved. For this purpose, values recorded in 1-min frequency are clustered on an hourly basis to smooth transitory effects while the performance is simulated by the model describing different periods in the day.

The model was initially validated through experimental testing carried out by comparing simulated $T_{\text {out }}$ values with experimentally monitored temperatures. For three consecutive days in summer with active $6 \mathrm{~m}^{2}$ and $18 \mathrm{~m}^{2}$ surfaces, the model provided very good matching [30]. For the current parametric study, aimed to understand the effect when changing external environmental conditions on the ASTF's performance, additional verifications were performed considering different days throughout the year. Figure 5 shows the correlation between simulated and experimental values for $T_{\text {out }}$.

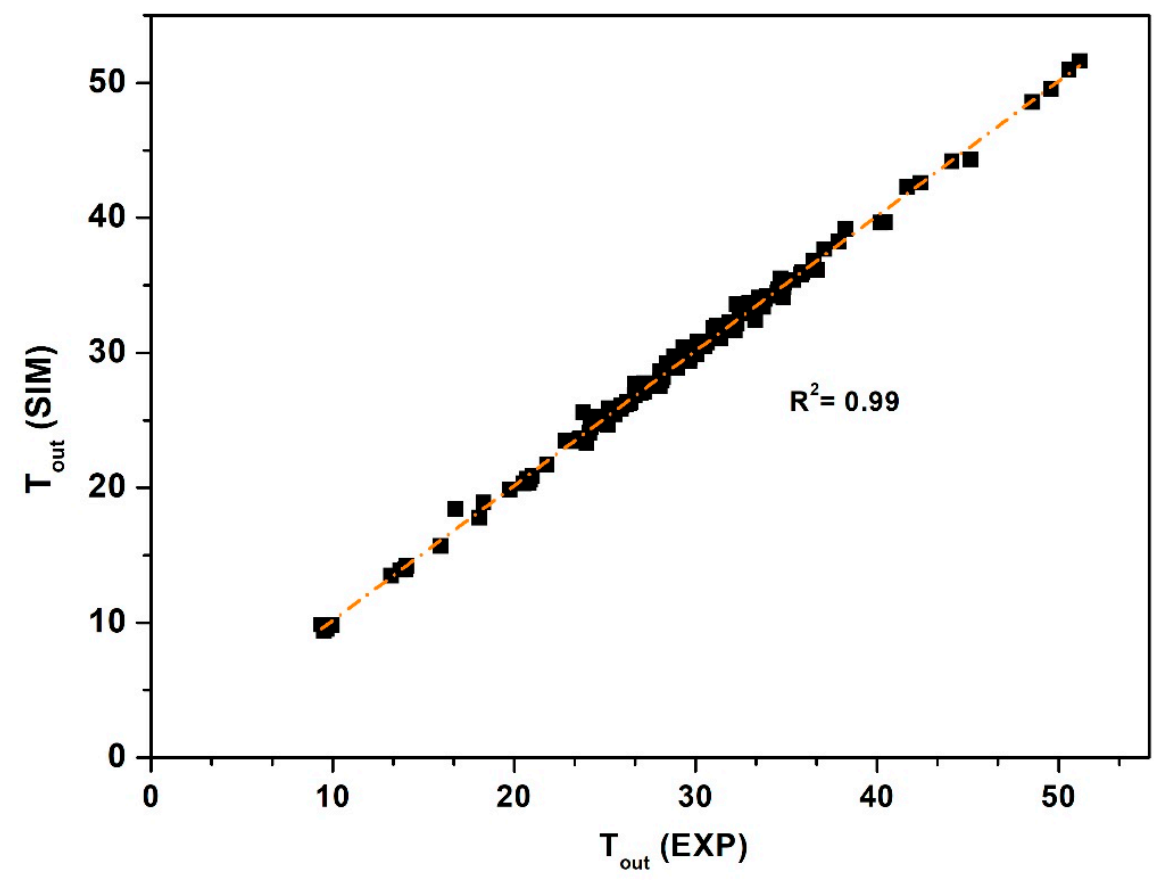

Figure 5. Comparison of simulated and experimentally measured temperatures for fluid on the outlet of the collector in the ASTF.

The parametric study developed for the analysis of dynamic parameters considers values within a realistic range, with the aim of quantifying their influence on the collector's performance as well as on the thermal difference achieved. A baseline was selected for the set of five parameters which gives an efficiency $(\eta)$ of 0.43 and temperature difference $\left(T_{\text {out }}-T_{\text {in }}\right)$ of $2.8^{\circ} \mathrm{C}$.

Taking this baseline as a reference (Table 3 ) the study was developed by modifying one of the parameters at each time, while the rest are fixed. In such a way, the potential of each measurement to 
harness solar energy is evaluated and each parameter with its different level of impact is highlighted, to clearly identify those of higher relevance.

Table 3. Baseline, maximum, and minimum values for the performed parameters.

\begin{tabular}{cccc}
\hline Parameter & Baseline Values & Lower Limit & Upper Limit \\
\hline Solar irradiation $\left(l_{s o l}\right)$ & $600 \mathrm{~W} / \mathrm{m}^{2} \mathrm{~K}$ & $100 \mathrm{~W} / \mathrm{m}^{2} \mathrm{~K}$ & $1000 \mathrm{~W} / \mathrm{m}^{2} \mathrm{~K}$ \\
Wind speed $\left(V_{W}\right)$ & $1.5 \mathrm{~m} / \mathrm{s}$ & $1 \mathrm{~m} / \mathrm{s}$ & $6 \mathrm{~m} / \mathrm{s}$ \\
Fluid inlet temperature $\left(T_{i n}\right)$ & $15^{\circ} \mathrm{C}$ & $10^{\circ} \mathrm{C}$ & $45^{\circ} \mathrm{C}$ \\
Ambient temperature $\left(T_{a m b}\right)$ & $14^{\circ} \mathrm{C}$ & $5{ }^{\circ} \mathrm{C}$ & $40^{\circ} \mathrm{C}$ \\
Mass flow rate $(\dot{m})$ & $0.13 \mathrm{~kg} / \mathrm{s}$ & $0.04 \mathrm{~kg} / \mathrm{s}$ & $0.2 \mathrm{~kg} / \mathrm{s}$ \\
\hline
\end{tabular}

\subsection{Experimental Assessment of the Combined System under Coupled and Uncoupled Operation Modes}

The experimental assessment is based on the performance analysis of the ASTF and the COP of the heat pump, comparing two different scenarios: when they operate as independent devices and later when they are coupled. The extensive experimental campaign carried out for several months during 2017 and 2018 under variable environmental conditions and different operating modes offers a valuable opportunity to provide such comparative analysis. This second part of the research is developed as an analysis of the experimentally recorded data during the tests carried out, based on the interpretation of the achieved results. Therefore, the model used for the parametric analysis is not employed in this case.

To make the comparison possible, two requirements are needed: (1) equivalent days regarding external environmental conditions but (2) with different working conditions. The second condition is controlled during the experimental testing by connecting or disconnecting the heat pump but the first one is fully governed by real weather conditions.

The review of the information collected during the experimental campaign identified two equivalent days fulfilling both requirements with different working conditions but for very similar environmental conditions. A difference of almost one year on a clear sunny day provides this possibility. When looking at the data collected during 2017 and 2018 respectively, a rather similar pattern can be appreciated between the 17 June 2017 average ambient temperature $\left(T_{e}\right)$ of $21.18{ }^{\circ} \mathrm{C}$ and solar irradiance $\left(I_{\text {sol }}\right)$ of $\left.3.178 \mathrm{kWh} / \mathrm{m}^{2}\right)$ and the 26 June 2018 average ambient temperature $\left(T_{e}\right)$ of $20.57^{\circ} \mathrm{C}$ and solar irradiance $\left(I_{s o l}\right)$ of $3.137 \mathrm{kWh} / \mathrm{m}^{2}$. Figure 6 represents the evolution for ambient temperature and solar irradiance in the south vertical facade for both reference days.

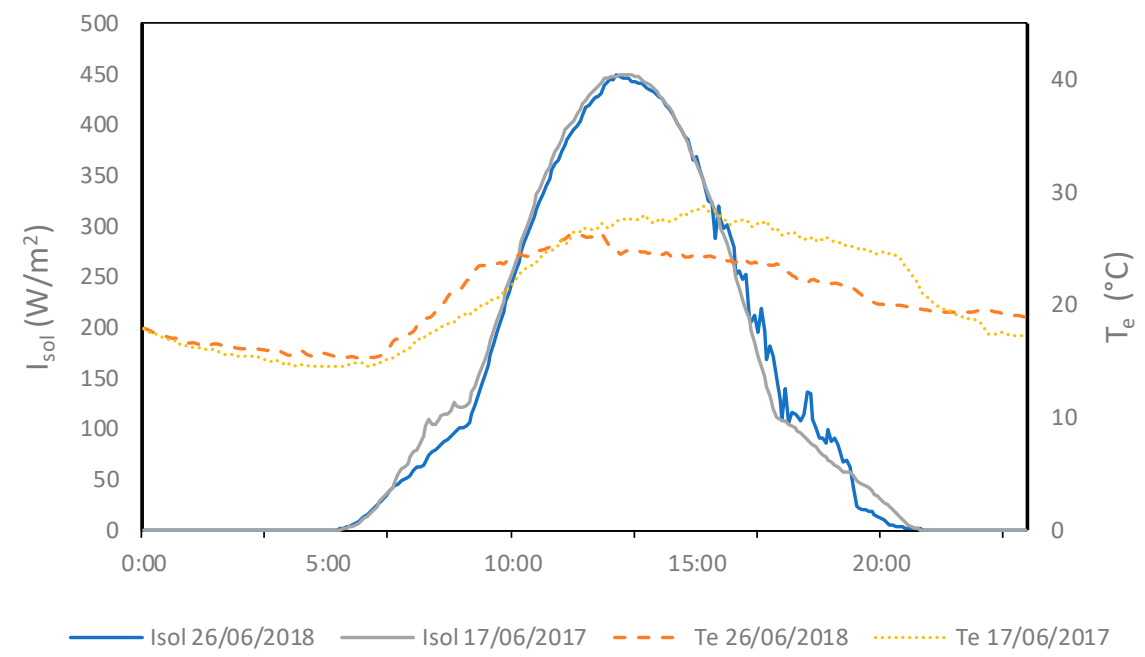

Figure 6. Comparison of environmental conditions for the two days analyzed. 
The day in 2017 (Day 1) was operated with a "disconnected heat pump" working mode while the other day in 2018 (Day 2) was operated with a "connected heat pump" mode. For the first one, just the solar circuit keeps working while the heat pump is switched off. The solar storage tank is then charged to a maximum value and as there is no energy-demanding load, the storage keeps the heat inside. Figure 7 shows this case for Day 1 where the peak value on the temperature arises some few hours after the maximum irradiance due to the inertia of the fluid inside the circuit. After that peak temperature a cooling effect in the storage tank can be appreciated due to a continuous operation of the circulating pump even in the absence of irradiance, resulting in a steeper temperature decrease after the maximum value is reached. Nevertheless, in order to appreciate the effect on the temperature's evolution if the continuous operation of the pump did not occur, the thermal losses due to the storage's efficiency were estimated (dotted line in Figure 7) considering that the circulating pump was switched off once the maximum temperature was achieved.

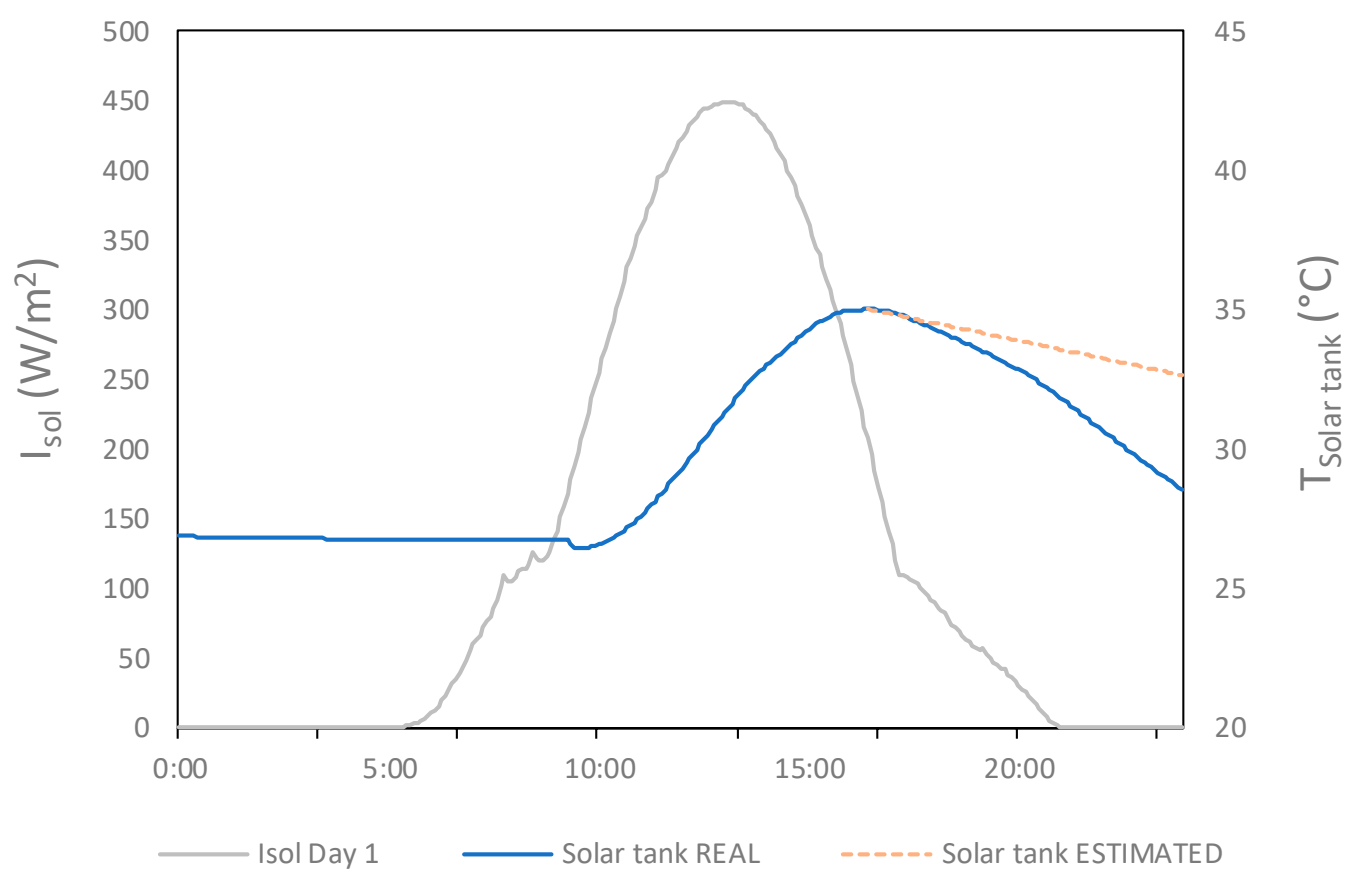

Figure 7. Temperature evolution in the solar storage tank during Day 1 (real and estimated cooling after maximum value).

In the case with a connected load, a DHW consuming pattern demands energy from the heat pump in eight different moments of the day, providing a total of $33.27 \mathrm{kWh}$ of useful thermal energy. The source of the heat pump extracts the heat from the solar tank reducing the average temperature of that tank. Figure 8 represents the temperature profiles in both tanks (the solar and the DHW tank) as well as the accumulated thermal energy produced by the heat pump for DHW purposes. 


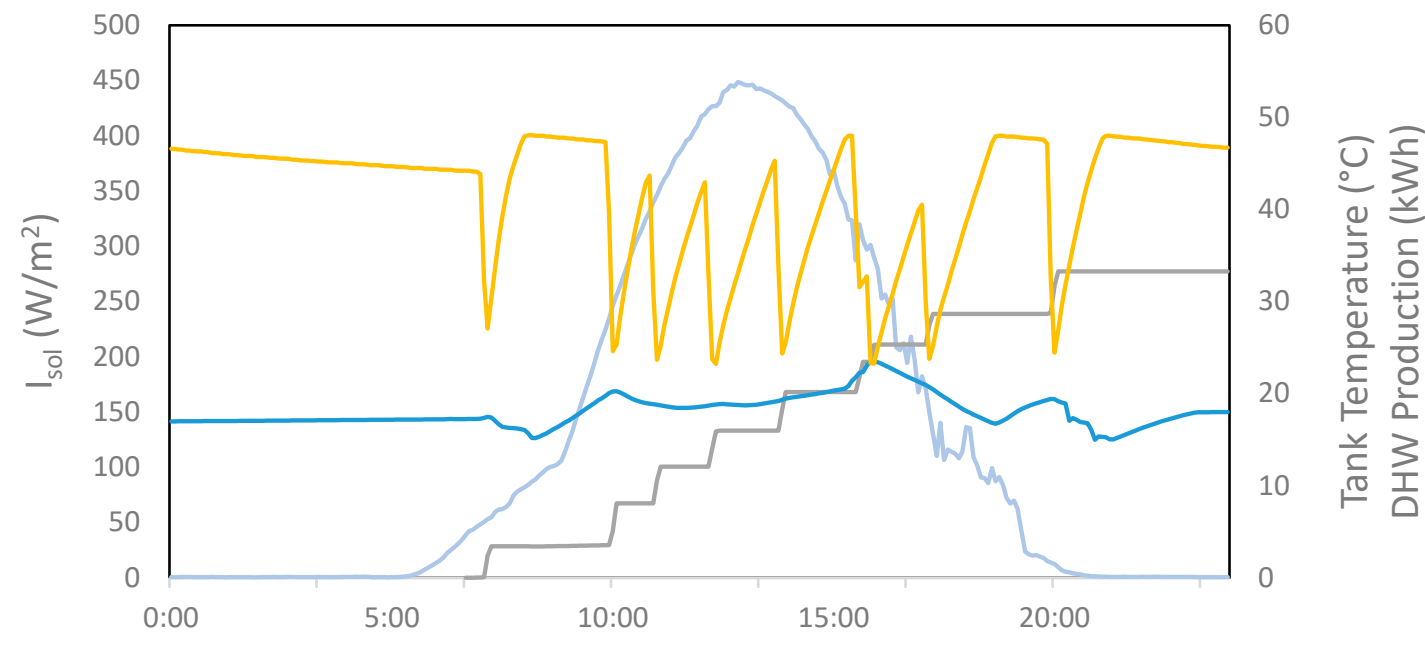

—Isol 26/06/2018_- Accumulated DHW prod. — Solar tank Temp. — DHW tank Temp.

Figure 8. Temperature evolution in the solar storage tank and the DHW tank and accumulated DHW energy output in Day 2.

The calculation procedure for the comparative assessment consists of the processing and combination of the data recorded in different days. Aiming to represent the performance of the two main components under study, the useful energy produced is calculated for the ASTF while the $\mathrm{COP}$ is representative of the heat pump's response.

For the ASTF, the production $(Q)$ of the panels is estimated using the temperature difference between the output and the input $\left(T_{\text {out }}-T_{\text {in }}\right)$ as well as the mass flow rate $(\dot{m})$. With those parameters, productions are calculated (Equation (2)) for both days.

For the case of the heat pump, the COP measured in Day 2 under load conditions (Equation (3)) is compared against theoretical COP values as there are no real data available for Day 1 as the heat pump is off. Therefore, two different and comparable technologies are considered according to the simplified models depending on the thermal jump as provided by Staffell et al. [32]. It is also important to take into consideration that those are maximum values and that for to real service conditions, results are in general significantly lower [32].

\section{Results}

\subsection{Parametric Assessment of the ASTF}

The parametric study shows the difference between inlet and outlet water temperature $\left(T_{\text {out }}-T_{\text {in }}\right)$ together with collector's efficiency $(\eta)$. Thermal difference also represents the heat transfer according to Equation (1). The results are provided for each variable parameter, distinguishing between dynamic design parameters and dynamic environmental parameters.

\subsubsection{Dynamic Designs Parameters}

Dynamic design parameters are those that can be configurated when the system is running. Once the design of the complete assembly is fixed and defined, the fluid inlet temperature and mass flow rate are those parameters that can be varied.

As described in Figure 9, when the inlet water temperature increases 35 degrees (from 10 to $45^{\circ} \mathrm{C}$ ), the temperature difference decreases, whereas the efficiency of the collector also decreases. The temperature drops down from 3.23 to $0.49^{\circ} \mathrm{C}$ and the efficiency from 0.49 to 0.07 , respectively. Thus, 
a linear trend between the fluid inlet temperature, together with the heat transfer and the efficiency is appreciated.

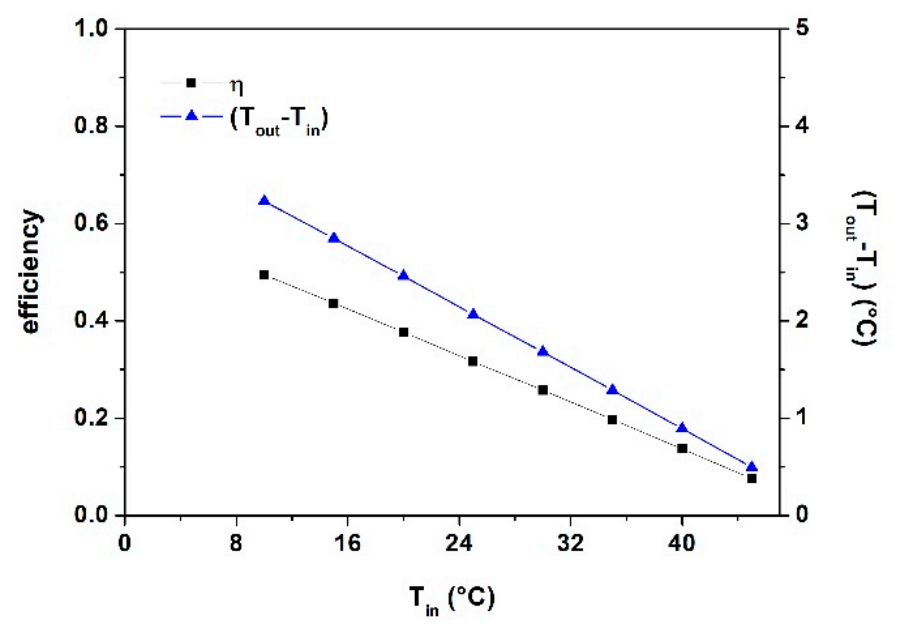

Figure 9. Results of the parametric study. Efficiency and temperature difference vs. fluid inlet temperature.

On the other hand, when the mass flow rate rises from $0.04 \mathrm{~kg} / \mathrm{s}$ to $0.2 \mathrm{~kg} / \mathrm{s}$ an increase in efficiency from 0.34 to 0.46 occurs, while $\left(T_{\text {out }}-T_{\text {in }}\right.$ ) decreases from 7.45 to $1.99{ }^{\circ} \mathrm{C}$ (Figure 10). The opposite trend between heat transfer and efficiency obtained is similar to results achieved by equivalent studies $[4,33,34]$. The main consequence of this situation is that, for high flow rates, the heat transfer is lower because the temperature increase in the fluid outlet is less pronounced since the conduction effect is more limited. Even with this reduction in the thermal jump, the increase in the flow implies that the efficiency is higher in absolute terms.

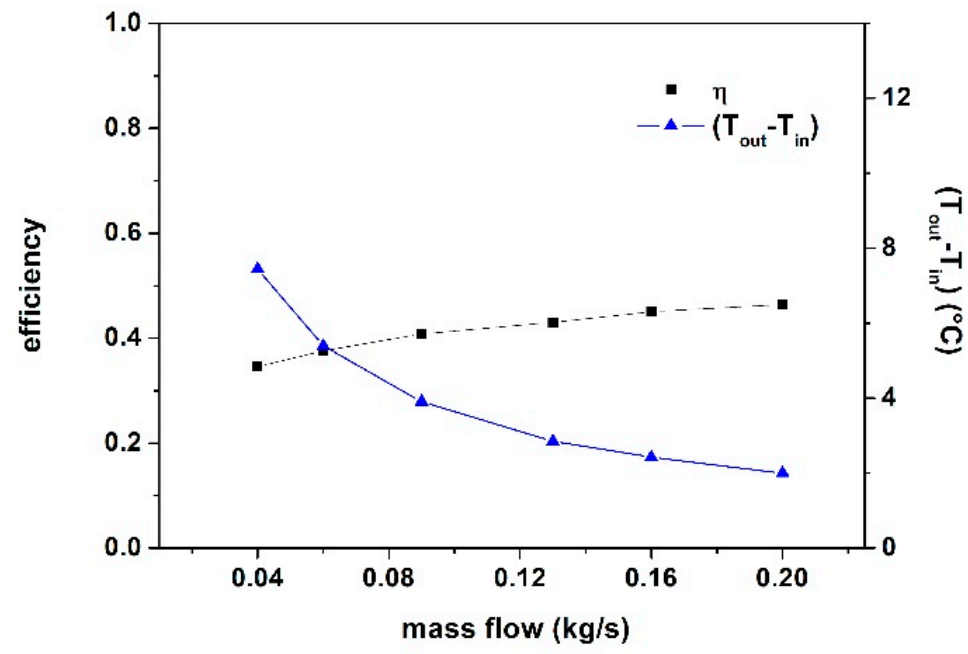

Figure 10. Results of the parametric study. Efficiency and temperature difference vs. mass flow rate.

\subsubsection{Dynamic Meteorological Parameters}

Unlike dynamic design parameters, meteorological parameters cannot be controlled. On the other hand, these parameters can be predicted. Based on recorded values through the experimental campaign, maximum and minimum values for ambient temperature, solar radiation, and wind speed were selected (Table 3) and the collector behavior was estimated in this case.

Figure 11 shows the variation of efficiency and temperature difference due to ambient temperature changes. When the ambient temperature varies from 5 to $40{ }^{\circ} \mathrm{C}$, both parameters increase from 0.34 
to 0.72 for the efficiency and from 2.22 to $4.73{ }^{\circ} \mathrm{C}$ for the temperature difference, showing a linear tendency in both cases.

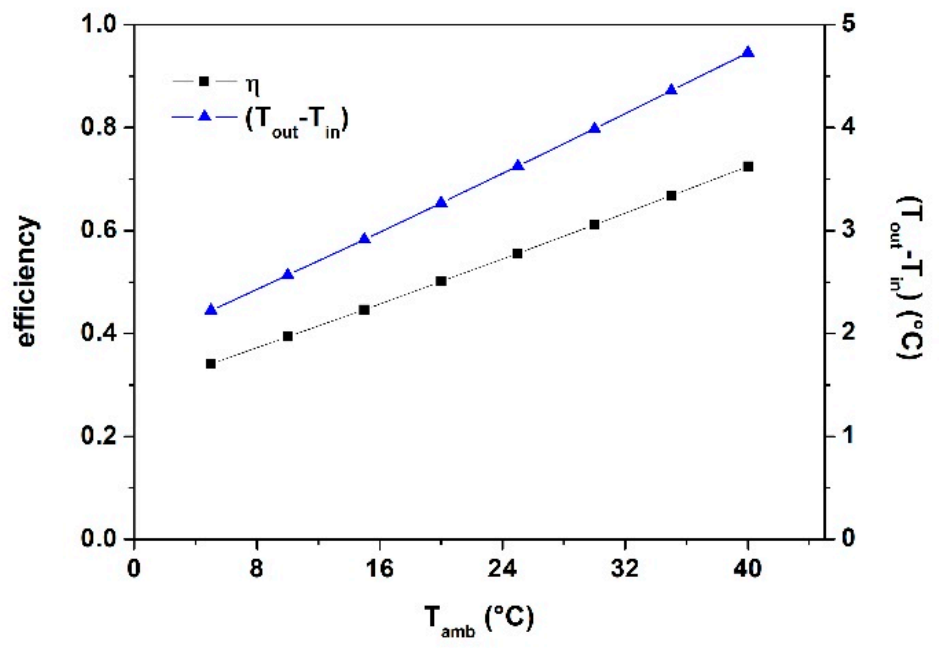

Figure 11. Results of the parametric study. Efficiency and temperature difference vs. ambient temperature.

The solar irradiation apparently can be considered as one of the most influencing parameters because it is the main source providing energy to the collector. A significant effect can be appreciated for the case of temperature difference $\left(T_{\text {out }}-T_{\text {in }}\right)$ [29] and consequently the increase of irradiation implies a higher energy output, but the impact is less significant on the efficiency. Even for big increases of irradiation (Figure 12) from $100 \mathrm{~W} / \mathrm{m}^{2} \mathrm{~K}$ to $1000 \mathrm{~W} / \mathrm{m}^{2} \mathrm{~K}$, the efficiency barely changes from 0.40 to 0.43 , while the $\left(T_{\text {out }}-T_{\text {in }}\right)$ linearly rises up strongly from 0.44 to $4.71^{\circ} \mathrm{C}$. A ten times variation in the irradiance implies the same proportional variation in the thermal difference with a linear relation, but just a small variation of three percentual points is perceived in the efficiency.

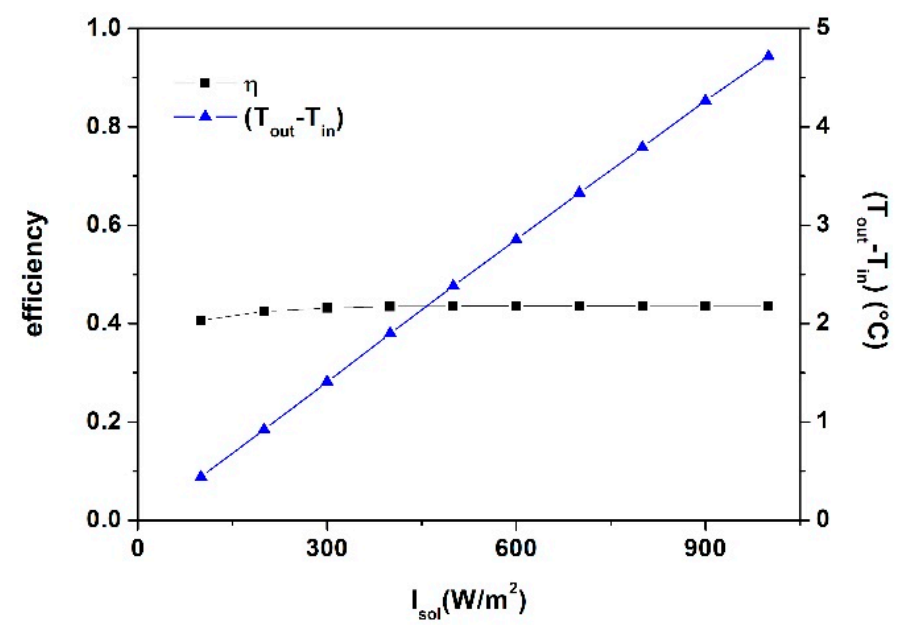

Figure 12. Results of the parametric study. Efficiency and temperature difference vs. solar irradiation.

The wind effect [35] was taken into account for velocities ranging from 1 to $6 \mathrm{~m} / \mathrm{s}$. When the wind is higher, the efficiency and temperature differences are lowered (Figure 13) due to losses associated with the convective effect (Equation (8)). The progression indicated for the wind implies reductions on the efficiency and temperature from 0.46 to 0.27 and 3.06 to $1.8^{\circ} \mathrm{C}$, respectively. This trend is similiar to assessments made by other authors $[36,37]$. 


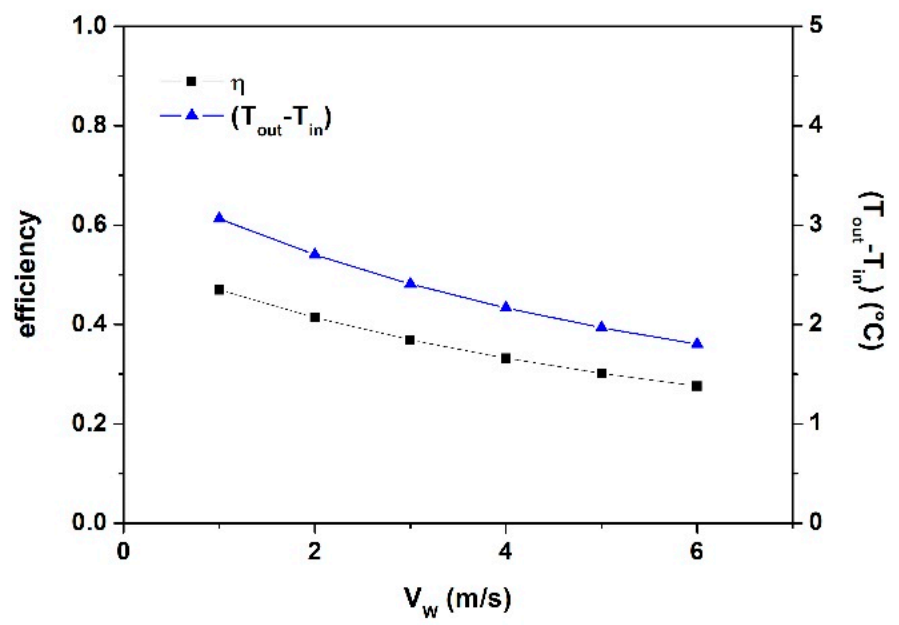

Figure 13. Results of the parametric study. Efficiency and temperature difference vs. wind speed.

\subsection{Experimental Assessment Performance of the System Combining ASTF Coupled to a Heat Pump}

The difference in the performance of the ASTF for two similar days is shown in Figure 14 where the energy collected by the solar facade on each day is represented, highlighting a day with no load (Day 1) compared with another day where the heat pump is delivering heat (Day 2) for DHW (as was previously depicted in Figure 8). For almost the same amount of available irradiance, the collector coupled to the heat pump collects 5.6 times more energy compared with the case with no load. Therefore, the efficiency of the collector follows the same tendency. The specific energy extracted for both scenarios as well as efficiencies are described in Table 4.

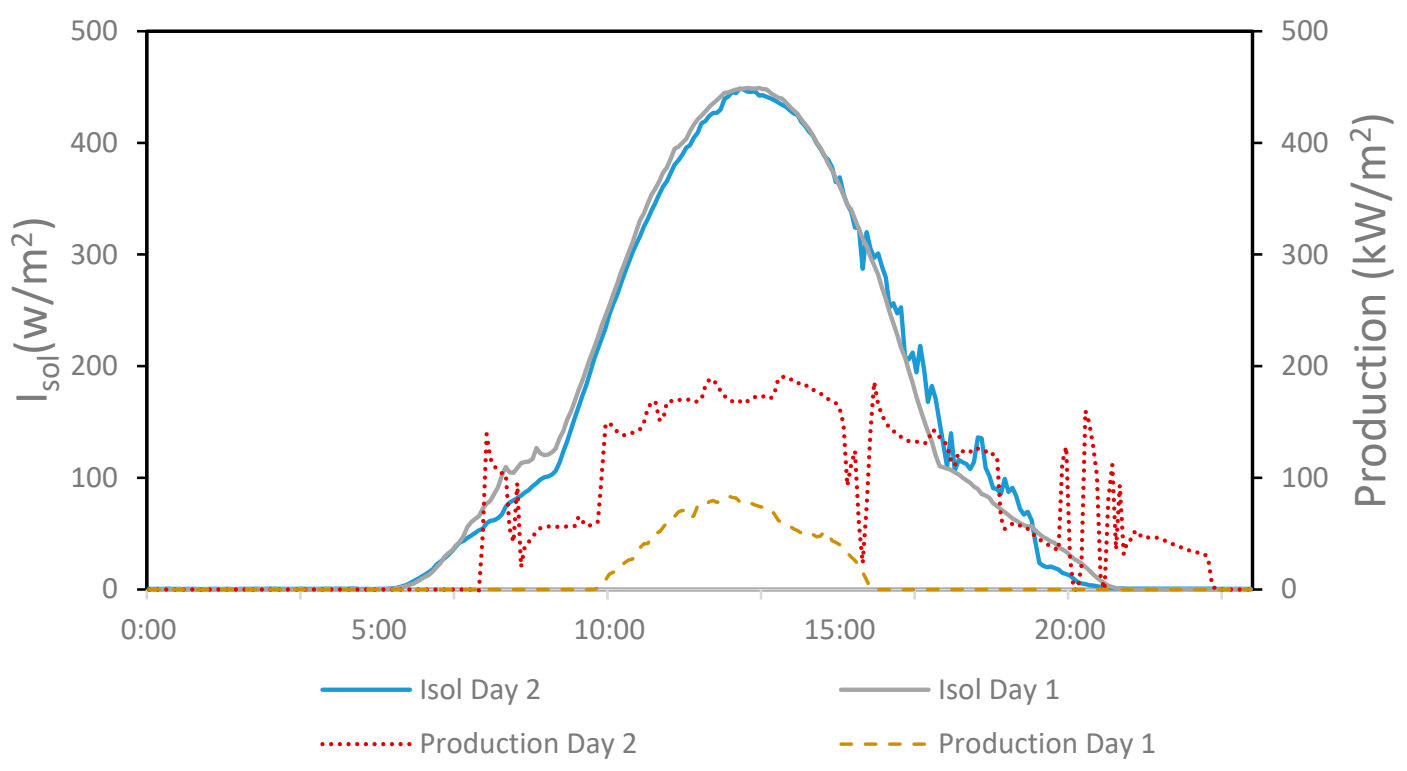

Figure 14. Experimental results for the irradiance and solar production during Days 1 and 2.

Table 4. Comparison of the efficiency and energy harnessed by the ASTF.

\begin{tabular}{ccc}
\hline & Day 1 & Day 2 \\
\hline Incident radiation $\left(\mathrm{kWh} / \mathrm{m}^{2}\right)$ & 3.178 & 3.137 \\
Collected energy $\left(\mathrm{kWh} / \mathrm{m}^{2}\right)$ & 0.307 & 1.722 \\
Efficiency of the collector $(\%)$ & 0.10 & 0.55 \\
\hline
\end{tabular}


The measured maximum $C O P$ value considers just the electricity consumed by the heat pump $\left(C O P_{M A X}\right)$ using the coupled system during Day 2. The estimated values for geothermal (ground source heat pump (GSHP)) and air-based (air source heat pump (ASHP)) solutions considering the theoretical values are displayed in Table 5 showing the differences in the performance of the alternative solutions for the heat pump. Moreover, the overall system's measured COP (COP $\left.P_{S Y S}\right)$ is also described when the electricity consumed by the solar loop and the rest of the components are also added to estimate the efficiency (Equations (4) and (5)).

Table 5. Coefficient of performance (COP) values for experimental values on Day 2 and estimated values for that day. GSHP: ground source heat pump; ASHP: air source heat pump.

\begin{tabular}{cc}
\hline & COP \\
\hline Measured $C O P_{M A X}$ for Day 2 & 4.76 \\
Estimated $C O P_{M A X}$ for GSHP & 5.18 \\
Estimated COP & 3.94 \\
Measured $C O P_{S Y S}$ for ASHP & 3.99 \\
\hline
\end{tabular}

The overall energy balance for Day 2 represents a total useful DHW consumption of $33.27 \mathrm{kWh}$, as well as an electric consumption of $7.69 \mathrm{kWh}$ and $1.24 \mathrm{kWh}$ for the heat pump and auxiliary components, respectively. This electric consumption of other consuming devices is split in $0.35 \mathrm{kWh}$ for the solar loop's circulating pump and $0.89 \mathrm{kWh}$ for the supply and exhaust air modules. This case represents an intensive productive scenario providing heat for DHW purposes. This implies a total of 14 working hours for the heat pump between 7:10 am to 9:10 pm where the available irradiation and heat production instants are coincident, in a schedule representative of residential use. When the matching between energy collection and energy production is not achieved, either because the production is required at night time or because there is a cloudy day, the storage tank size represents one of the key aspects for the design optimization.

\section{Discussion}

The result of the parametric assessment identifies that those parameters with the highest effect on heat transfer rates are the solar irradiation and mass flow. Temperature differences of up to 4.27 and $5.44{ }^{\circ} \mathrm{C}$ are achieved respectively between the limit values considered. Other parameters affecting the temperature with lower relevance are, fluid inlet temperature $\left(2.77^{\circ} \mathrm{C}\right)$, ambient temperature $\left(2.5^{\circ} \mathrm{C}\right)$, and wind speed as the least influencing one $\left(1.26^{\circ} \mathrm{C}\right)$.

Regarding efficiency, the fluid inlet temperature and ambient temperature display the greatest variance, giving a maximum variation of 0.41 and 0.38 respectively, followed by wind speed (0.19), mass flow (0.11), and solar irradiation (0.03).

Consequently, the temperature difference and the energy collected is maximized when solar irradiation and ambient temperature present higher values while mass flow, fluid inlet temperature, and wind speed are minimum. If efficiency is the factor that wants to be maximized, the reduced fluid inlet temperature together with high ambient temperatures and calm wind speeds are desirable. The influence of the mass flow rate in the efficiency is less significant, since the effect of the irradiance is negligible.

It is relevant to highlight that those parameters with the highest impact in the temperature difference (mass flow and solar irradiation) represent the lowest impact on efficiency. Figures 15 and 16 display the performance of the maximum and minimum values for each of the five dynamic variables assessed, thus displaying the most influential ones. 


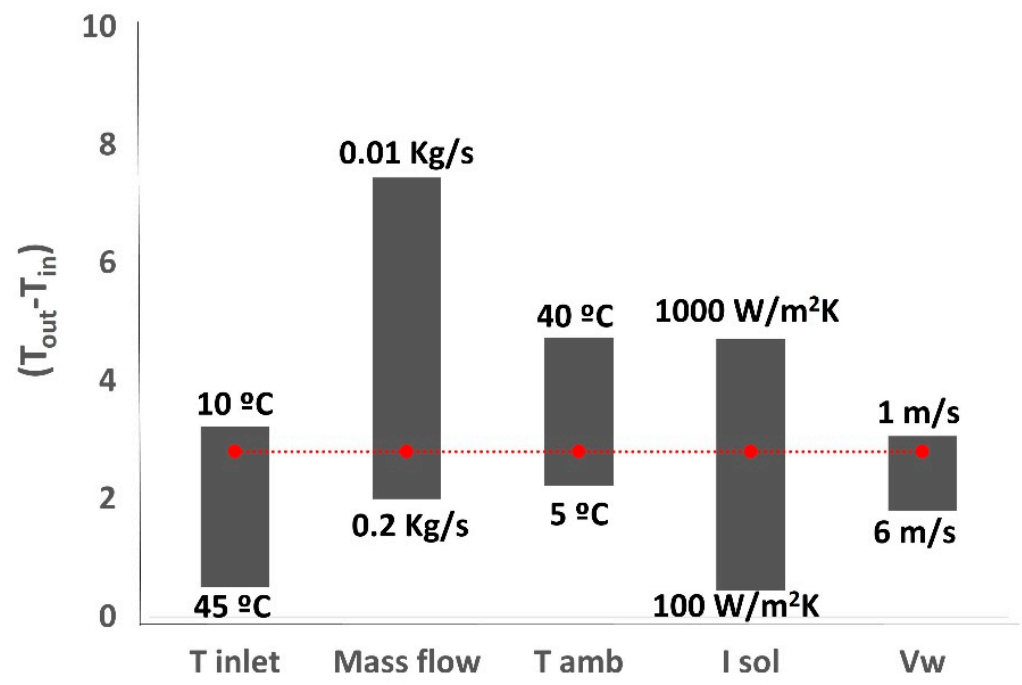

Figure 15. Summary of the parametric study representing the maximum and minimum achievable thermal difference $\left(T_{\text {out }}-T_{\text {in }}\right)$.

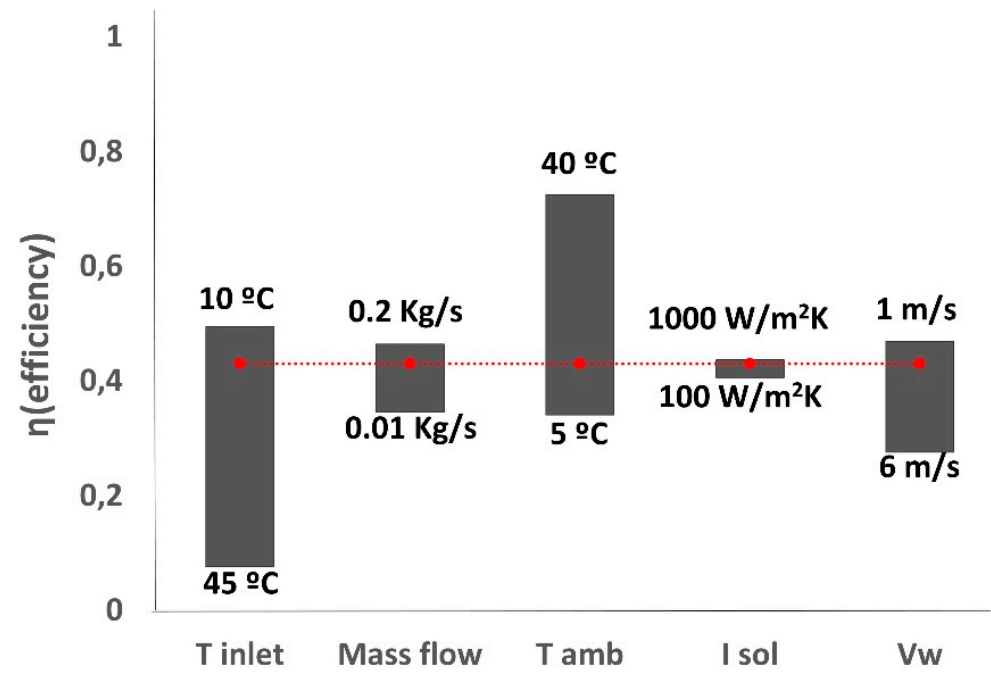

Figure 16. Summary of the parametric study representing the maximum and minimum achievable efficiency values.

For the case of the experimental assessment of the coupled and decoupled system, the measured values for the two selected days demonstrated that, for the ASTF, the yield can significantly increase from $10 \%$ to $55 \%$ and the total energy collected is 5.6 times higher. For the heat pump, although quite close, the COP level for a theoretical geothermal case was not achieved with the tested SAHP solution. However, it is worth noticing that the real performance of heat pumps is in general below those theoretical values.

These results are fully dependent on the case studied and energy produced and time required by the heat pump to provide that heat. Even if there is a quite low possibility to get many additional comparable days with a one-year difference as in the case presented, the assessment of the coupled system's behavior should be directly studied even if there is no reference day for the uncoupled working mode.

As a final contribution, Figure 17 provides information about two additional days under coupled operation mode that did not match with comparable days with the uncoupled mode. Even if a similar comparison as the one assessed for Days 1 and 2 cannot be performed in this case to quantify the 
changes on the efficiency and COP, these two days are presented as they provide additional and valuable information about the production capabilities of the SAHP system. Even with less available irradiance (23\% lower), Day 3, also in summer, represents a total daily DHW production of $46.7 \mathrm{kWh}$ and a $C O P_{M A X}$ of 4.77 for $2.0 \mathrm{kWh}$ energy collected by the ASTF. During Day 4 in winter, the production is $21.03 \mathrm{kWh}$, the $C O P_{M A X}$ is 4.47 , and the energy harnessed by the collectors is $0.61 \mathrm{kWh}$.
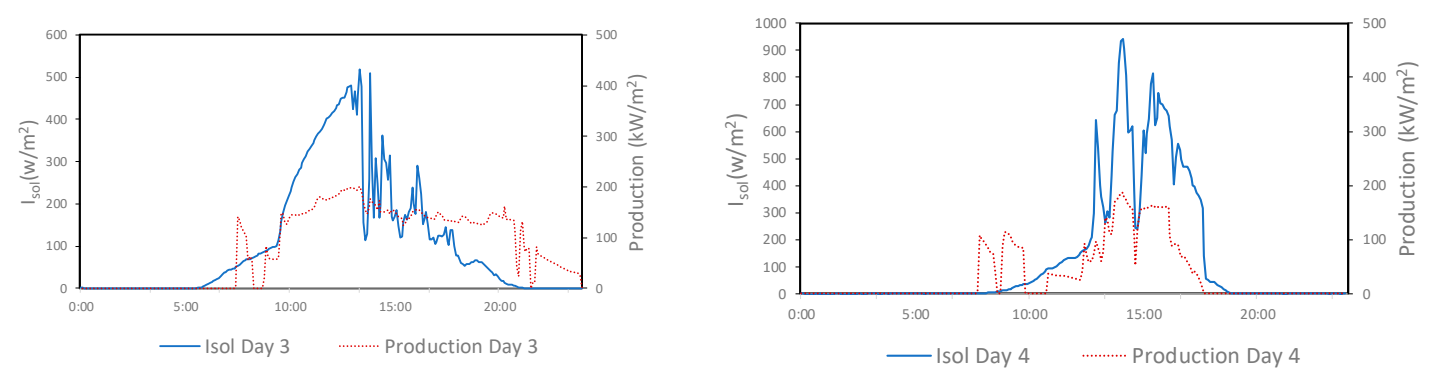

Figure 17. Experimental results for the irradiance and the solar production during Days 3 and 4 .

The study presented here is part of an active research initiative, where ASTF concepts are considered as interesting and competitive solutions to be adopted when renewable energies for buildings are valuated. Even if other systems and technologies are available in the market, such as conventional flat plate and vacuum collectors, the system suggested represents an innovative alternative based on low-temperature collectors integrated into sandwich panels. In such a way the benefit of a low-cost facade and a collector together with a reduced and simplified operation is achieved, although the solar yield is also smaller when compared to collectors operated at higher temperatures.

The main aim of the analysis performed is to properly understand and quantify the response of this solution under different working conditions and when coupled to a heat pump. This information evaluates the proposed system as a feasible alternative to other solutions that are less competitive and/or technically not possible in certain cases. The limitations of space are a clear restriction for roof placed collectors in dense urban environments, while radiated surface on facades is still unexploited. In parallel, limitations for geothermal systems are also present, especially in renovation, due to high costs or space constraints.

To identify conditions and scenarios where the ASTF performs best as well as the energy that can be achieved, a parametric assessment was first developed. The necessity to properly regulate the mass flow rate and inlet fluid temperature were stated, while the most convenient external environmental conditions for energy production were also identified. This information represents a valuable input when these ASTFs are proposed for building designs as well as for the operation of the collector once installed.

Additionally, implications for a combined ASTF and heat pump solution were identified. Based on experimentally obtained data, improvement on the ASTF performance was demonstrated while the $\mathrm{COP}$ of the heat pump remains on a quite high level. Moreover, there is still room for improvement as similar experiences [38] highlighted that alternative ways to interconnect components and/or operate them can provide optimized efficiencies.

As a conclusion, the interest of considering the suggested system as a valid and competitive alternative to ground source or air source heat pumps was preliminary identified, while the increase on the ASTF performance was demonstrated.

The research activity for the coupled system is still ongoing, aiming to better characterize the response of the combined solution. The cases presented are three example days and additional research considering other production profiles, together with different environmental conditions, are necessary to better understand the possibilities of the combined SAHP system. Especially the overall potential of the solution and its limitation must be studied as well as the implications for extreme conditions. In winter, with low temperatures and no irradiance, prevention measurements are suggested based 
on the solutions employed by the heat pump technology (electrically-driven defrosting system or alcohol-based mixtures). In summer, the positioning of the collector oriented vertically south implies that the higher radiation peaks are not coincident with the hot months, therefore the overproduction issues are less significant allowing more balanced designs for heat production.

A wider characterization of the system will allow to estimate the performance of the overall system for different scenarios and to compare it with alternative concepts. The main goal is to demonstrate the possibilities of the system conceived, aiming to provide additional solutions to designers and building users. The results obtained in this case indicate that the potential of the system to compete with those technologies is relevant enough and therefore, there is a need to completely address the analysis of the system.

\section{Conclusions}

The research developed and presented here is a detailed analysis about the efficiency of an Active Solar Thermal Facade (ASTF) working under different boundary conditions. The result is a two-step analysis. First, a parametric assessment for the active facade application for different dynamic design and meteorological parameters was carried out. Based on a previously built and validated numerical model, the influence of variating these parameters in the heat transfer $\left(T_{\text {out }}-T_{\text {in }}\right)$ and efficiency was quantified. Secondly, an experimental test was performed, based on an extensive testing campaign in our facilities, which studied the benefits in the performance of the ASTF and energy production. The active facade was first monitored as an independent component to later analyze a coupled operation mode together with a heat pump, demonstrating that the combination provides benefits on the performance for both technologies.

The relevant conclusions of the parametric study are that there are a set of parameters fully governed by environmental conditions (irradiance, ambient temperature, and wind speed) that have a significant influence on the behavior of the ASTF. On the other hand, there are some other parameters that can be controlled during the operation of the ASTF (fluid inlet temperature and mass flow rate). The challenge of a continuous configuration of these adaptable values depending on the external situation strongly contributes to achieving higher performances for the ASTF.

In addition, the experimental assessment provided very relevant results about the performance of the system combining the ASTF with a heat pump. The active facade's performance was multiplied by 5.5. In the same line, the energy collected by the panels experienced a similar progression from 0.307 to $1.722 \mathrm{kWh} / \mathrm{m}^{2}$.

For the heat pump, although quite close, the COP level for a theoretical geothermal case was not achieved in this case. However, it is worth noticing that the real performance of heat pumps is in general below the theoretical values and the potential of the combined system is very significant in this case. Consequently, the interest of considering the suggested SAHP system as a valid alternative to ground source or air source heat pumps was described.

Solar energy on the one hand and heat pumps on the other demonstrated the high potential for improving the efficiency of buildings, but the synergetic combination of both technologies is a clear opportunity to boost the performance of coupled systems.

Although the case is mainly limited to a comparison between two days, and further study is needed on different environmental conditions, as well as on heating production profiles, the results obtained are very promising in the way towards more efficient and sustainable buildings. The research activity in this field is still ongoing and aimed at better characterizing the system and its components for those alternative working scenarios and information about two additional days was also anticipated.

Author Contributions: Conceptualization and methodology, P.E.; simulations, A.L.; data acquisition and assessment, P.E. and A.L.; validation and supervision, J.M.B. and J.A.C.; writing-original draft, P.E. and A.L.; writing-review, editing, and approval of final version, all authors. All authors have read and agreed to the published version of the manuscript. 
Funding: This research was partially funded by the Basque Government through IT781-13 and IT1314-19 research groups and by the University of the Basque Country UPV/EHU through PES17/25. Additionally, TECNALIA Research \& Innovation supported the research activities research through a cooperation agreement (PT10516) with $\mathrm{UPV} / \mathrm{EHU}$

Acknowledgments: This paper is a result of a long process of research activities that started with a research project (BASSE) — Grant Agreement no: RFSR-CT-2013-00026, developed between 2013 and 2016. The authors would like to thank all the companies and researchers participating in that project for their strong involvement during the research. Results from BASSE project have inspired the present research.

Conflicts of Interest: The authors declare no conflicts of interest.

\section{Nomenclature}

\begin{tabular}{|c|c|}
\hline$C_{w}$ & Specific heat capacity of the water $\left(\mathrm{J} / \mathrm{kg}^{\circ} \mathrm{C}\right)$ \\
\hline COP & Coefficient of performance for the heat pump \\
\hline$C O P_{\text {sys }}$ & Coefficient of performance for the system \\
\hline$Q_{h}$ & Heat supplied by the condenser (W) \\
\hline$W_{c}$ & Associated electrical energy consumed by the heat pump (W) \\
\hline$W_{\text {aux }}$ & Associated electrical energy consumed by auxiliary components (W) \\
\hline$F M$ & Flowmeter \\
\hline$h_{f}$ & Convective heat transfer coefficient between fluid and pipe wall $\left(\mathrm{W} / \mathrm{m}^{2} \mathrm{~K}\right)$ \\
\hline$h_{w}$ & Convective heat transfer coefficient between absorber and ambient air $\left(\mathrm{W} / \mathrm{m}^{2} \mathrm{~K}\right)$ \\
\hline$V_{w}$ & Wind speed $(\mathrm{m} / \mathrm{s})$ \\
\hline$D_{w}$ & Wind direction \\
\hline$\lambda$ & Thermal conductivity $\left(\mathrm{W} / \mathrm{m}^{2} \mathrm{~K}\right)$ \\
\hline$Q$ & Heat power $(W)$ \\
\hline$m$ & Mass flow rate $(\mathrm{kg} / \mathrm{s})$ \\
\hline$I_{\text {sol }}$ & Solar irradiation $\mathrm{W} /\left(\mathrm{m}^{2}\right)$ \\
\hline$A_{c}$ & Collector area \\
\hline$q$ & Specific heat power $\left(\mathrm{W} / \mathrm{m}^{2}\right)$ \\
\hline$q_{f}$ & Heat flux absorbed by the fluid $\left(\mathrm{kW} / \mathrm{m}^{2}\right)$ \\
\hline$q_{\text {rad }}$ & Heat flux emitted by radiation effect $\left(\mathrm{KW} / \mathrm{m}^{2} \mathrm{~K}\right)$ \\
\hline$q_{\text {irad }}$ & Absorbed heat flux due to solar irradiance $\left(\mathrm{W} / \mathrm{m}^{2}\right)$ \\
\hline$T_{a m b}$ & Ambient temperature $\left({ }^{\circ} \mathrm{C}\right)$ \\
\hline$T_{\text {in }}$ & Inlet fluid temperature $\left({ }^{\circ} \mathrm{C}\right)$ \\
\hline$T_{\text {out }}$ & Outlet fluid temperature $\left({ }^{\circ} \mathrm{C}\right)$ \\
\hline$T_{a b s}$ & Surface temperature for the absorber $\left({ }^{\circ} \mathrm{C}\right)$ \\
\hline$T_{\text {sky }}$ & Sky temperature $\left({ }^{\circ} \mathrm{C}\right)$ \\
\hline$T_{f}$ & Fluid temperature $\left({ }^{\circ} \mathrm{C}\right)$ \\
\hline$T_{p}$ & Pipe wall temperature $\left({ }^{\circ} \mathrm{C}\right)$ \\
\hline$\Delta T$ & Thermal difference-heat transfer capacity $\left({ }^{\circ} \mathrm{C}\right)$ \\
\hline$\sigma$ & Stefan-Boltzmann constant $\left(5.6810-8 \mathrm{~W} / \mathrm{m}^{2} \mathrm{~K}^{4}\right)$ \\
\hline$\alpha$ & Absorptivity (-) \\
\hline$\varepsilon$ & Emissivity (-) \\
\hline$\eta$ & Efficiency (\%) \\
\hline
\end{tabular}

\section{References}

1. D'Agostino, D.; Mazzarella, L. What is a Nearly zero energy building? Overview, implementation and comparison of definitions. J. Build. Eng. 2019, 21, 200-212. [CrossRef]

2. Buonomano, A.; Forzano, C.; Kalogirou, S.A.; Palombo, A. Building-façade integrated solar thermal collectors: Energy-economic performance and indoor comfort simulation model of a water based prototype for heating, cooling, and DHW production. Renew. Energy 2018, 137, 20-36. [CrossRef]

3. Maurer, C.; Cappel, C.; Kuhn, T.E. Progress in building-integrated solar thermal systems. Sol. Energy 2017, 154, 158-186. [CrossRef]

4. Hegarty, R.; Kinnane, O.; Mccormack, S.J. Parametric investigation of concrete solar collectors for façade integration. Sol. Energy 2017, 153, 396-413. [CrossRef] 
5. Petrichenko, K.; Ürge-vorsatz, D.; Cabeza, L.F. Energy \& Buildings Modeling global and regional potentials for building-integrated solar energy generation. Energy Build. 2019, 198, 329-339. [CrossRef]

6. Elguezabal, P.; Arregi, B. An analysis of the potential of envelope-integrated solar heating and cooling technologies for reducing energy consumption in European climates. J. Facade Des. Eng. 2018, 6, 85-94. [CrossRef]

7. Lobaccaro, G.; Lisowska, M.M.; Saretta, E.; Bonomo, P.; Frontini, F. A Methodological Analysis Approach to Assess Solar Energy Potential at the Neighborhood Scale. Energies 2019, 12, 3554. [CrossRef]

8. Munari Probst, M.C.; Roecker, C.; Giovanardi, A.; Lundgren Wall, M. Designing Solar Thermal Systems for Architectural Integration. Criteria and Guidelines for Product and System Developers. 2013. Available online: http://task41.iea-shc.org/publications (accessed on 2 December 2019).

9. Ren, G.; Zhao, X.; Zhan, C.; Jin, H.; Zhou, A. Investigation of the Energy Performance of a Novel Modular Solar Building Envelope. Energies 2017, 10, 880. [CrossRef]

10. Gagliano, A.; Aneli, S.; Nocera, F. Analysis of the performance of a building solar thermal facade (BSTF) for domestic hot water production. Renew. Energy 2019, 142, 511-526. [CrossRef]

11. Giovanardi, A.; Passera, A.; Zottele, F.; Lollini, R. Integrated solar thermal façade system for building retrofit. Sol. Energy 2015, 122, 1100-1116. [CrossRef]

12. Lai, C.M.; Hokoi, S. Solar façades: A review. Build. Environ. 2015, 91, 152-165. [CrossRef]

13. Quesada, G.; Rousse, D.; Dutil, Y.; Badache, M.; Hallé, S. A comprehensive review of solar facades. Opaque solar facades. Renew. Sustain. Energy Rev. 2012, 16, 2820-2832. [CrossRef]

14. Quesada, G.; Rousse, D.; Dutil, Y.; Badache, M.; Hallé, S. A comprehensive review of solar facades. Transparent and translucent solar facades. Renew. Sustain. Energy Rev. 2012, 16, 2643-2651. [CrossRef]

15. Zhang, X.; Shen, J.; Lu, Y.; He, W.; Xu, P.; Zhao, X.; Dong, X. Active Solar Thermal Facades (ASTFs): From concept, application to research questions. Renew. Sustain. Energy Rev. 2015, 50, 32-63. [CrossRef]

16. Motte, F.; Notton, G.; Cristofari, C.; Canaletti, J. Design and modelling of a new patented thermal solar collector with high building integration. Appl. Energy 2013, 102, 631-639. [CrossRef]

17. Rodríguez-sánchez, D.; Belmonte, J.F.; Izquierdo-barrientos, M.A.; Molina, A.E.; Rosengarten, G. Solar energy captured by a curved collector designed for architectural integration. Appl. Energy 2014, 116, 66-75. [CrossRef]

18. Cappel, C.; Streicher, W.; Lichtblau, F.; Maurer, C. Barriers to the market penetration of façade-integrated solar thermal systems. Energy Procedia 2014, 48, 1336-1344. [CrossRef]

19. European Commission. 2013/114/EU: Commission Decision of 1 March 2013 Establishing the Guidelines for Member States on Calculating Renewable Energy from Heat Pumps from Different Heat Pump Technologies Pursuant to Article 5 of Directive 2009/28/EC of the European Parliament and of the Council. Available online: https://eur-lex.europa.eu/legal-content/EN/TXT/PDF/?uri=CELEX:32013D0114\&from=EN (accessed on 2 December 2019).

20. International Energy Agency. Solar Heating and Cooling Programme. IEA-SHC. Task 44. Solar and Heat Pump Systems. Available online: http://task44.iea-shc.org/ (accessed on 2 December 2019).

21. Wang, Z.; Guo, P.; Zhang, H.; Yang, W.; Mei, S. Comprehensive review on the development of SAHP for domestic hot water. Renew. Sustain. Energy Rev. 2016, 72, 871-881. [CrossRef]

22. Mohanraj, M.; Belyayev, Y.; Jayaraj, S.; Kaltayev, A. Research and developments on solar assisted compression heat pump systems-A comprehensive review (Part-B: Applications). Renew. Sust. Energy Rev. 2018, 83, 124-155. [CrossRef]

23. Yang, Z.; Wang, Y.; Zhu, L. Building Space Heating with a Solar-Assisted Heat Pump Using Roof-Integrated Solar Collectors. Energies 2011, 4, 504-516. [CrossRef]

24. Calise, F.; Dentice, M.; Damian, R.; Vanoli, L. Thermoeconomic optimization of a solar-assisted heat pump based on transient simulations and computer Design of Experiments. Energy Convers. Manag. 2016, 125, 166-184. [CrossRef]

25. Lerch, W.; Heinz, A.; Heimrath, R. Direct use of solar energy as heat source for a heat pump in comparison to a conventional parallel solar air heat pump system. Energy Build. 2015, 100, 34-42. [CrossRef]

26. Carbonell, D.; Haller, M.Y.; Frank, E. Potential benefit of combining heat pumps with solar thermal for heating and domestic hot water preparation. Energy Procedia 2014, 57, 2656-2665. [CrossRef] 
27. Boudjabeur, S. Building Active Steel Skin (BASSE); Grant Agreement n: RFSR-CT-2013-0026. Final Report; RFCS Publications, 2018; ISBN 978-92-79-94133-7. ISSN 1831-9424; Available online: https://publications. europa.eu/en/web/general-publications/publications (accessed on 2 December 2019). [CrossRef]

28. Elguezabal, P.; Garay, R.; Martin, K. Experimentation under real performing conditions of a highly integrable unglazed solar collector into a building façade. Energy Procedia 2017, 122, 775-780. [CrossRef]

29. Duffie, J.; Beckmann, W. Solar Engineering of Thermal Processes, 4th ed.; John Wiley \& Sons: Hoboken, NJ, USA, 2013.

30. Elguezabal, P.; Lopez, A.; Blanco, J.M.; Chica, J.A. CFD model-based analysis and experimental assessment of key design parameters for an integrated unglazed metallic thermal collector façade. Renew. Energy 2020, 146, 1766-1780. [CrossRef]

31. Brandl, D.; Schober, H.; Hochenauer, C. Analysis of Heating Effects and Deformations for a STAF Panel with a Coupled CFD and FEM Simulation Method. J. Facade Des. Eng. 2018, 6, 116-131. [CrossRef]

32. Staffell, L.I.; Brett, D.; Brandon, N.; Hawkes, A. A review of domestic heat pumps. Energy Environ. Sci. 2012, 5, 9291-9306. [CrossRef]

33. Gunjo, D.G.; Mahanta, P.; Robi, P.S. CFD and experimental investigation of $\mathrm{fl}$ at plate solar water heating system under steady state condition. Renew. Energy 2017, 106, 24-36. [CrossRef]

34. Chen, Z.; Furbo, S.; Perers, B.; Fan, J.; Andersen, E. Efficiencies of flat plate solar collectors at different flow rates. Energy Procedia 2012, 30, 65-72. [CrossRef]

35. Kumar, S.; Mullick, S.C. Wind heat transfer coefficient in solar collectors in outdoor conditions. Sol. Energy 2010, 84, 956-963. [CrossRef]

36. Rodríguez-Hidalgo, M.C.; Rodríguez-Aumente, P.A.; Lecuona, A.; Gutiérrez-Urueta, G.L.; Ventas, R. Flat plate thermal solar collector efficiency: Transient behavior under working conditions. Part I: Model description and experimental validation. Appl. Eng. 2011, 31, 2394-2404. [CrossRef]

37. Rodríguez-Hidalgo, M.C.; Rodríguez-Aumente, P.A.; Lecuona, A.; Gutiérrez-Urueta, G.L.; Ventas, R. Flat plate thermal solar collector efficiency: Transient behavior under working conditions part II: Model application and design contributions. Appl. Eng. 2011, 31, 2385-2393. [CrossRef]

38. Haller, M.Y.; Haberl, R.; Mojic, I.; Frank, E. Hydraulic integration and control of heat pump and combi-storage: Same components, big differences. Energy Procedia 2014, 48, 571-580. [CrossRef]

(C) 2020 by the authors. Licensee MDPI, Basel, Switzerland. This article is an open access article distributed under the terms and conditions of the Creative Commons Attribution (CC BY) license (http://creativecommons.org/licenses/by/4.0/). 